\title{
Familiarity Breeds Trust: Collective Action in a Policy Domain
}

\author{
Mark Lubell University of California, Davis
}

\begin{abstract}
Researchers are currently refining the concept and theory of trust to focus on identifying the bases of trust within specific domains. This paper examines the development of trust within the domain of agricultural water policy, where trust is a critical resource for solving collective action problems. The analysis uses data from a mail survey of farmers in agricultural water policy to integrate three theoretical frameworks: the conventional generalized trust perspective, Levi's transaction cost theory of trust, and Sabatier and Jenkins-Smith's Advocacy Coalition Framework. The results demonstrate that while there is a close relationship between the attitude of trust and beliefs about the behavior of policy actors, the dynamics of trust within policy domains should be understood within the context of institutional structures and competing political values.
\end{abstract}

$\tau$ $\mathrm{n}$ the past decade, the concept of trust has become a central topic of inquiry in political and many other social sciences. Often discussed under the broader rubric of "social capital," trust is conceptualized as a critical factor for solving the numerous collective action problems faced by citizens in modern political economies (Coleman 1990; Fukuyama 1995; Hardin 2002; Putnam 2001). Trust is believed to promote mutually beneficial interactions in the family and workplace (Granovetter 1983; Mondak and Mutz 2001), economic exchange (Fehr, Gachter, and Kirchsteiger 1997; North 1990), a variety of public policy settings like taxpaying (Levi 1988; Scholz and Lubell 1998a, 1998b) and environmental policy (Lubell 2003; Ostrom 1990; Scheberle 1997), and more fundamentally for citizens engaged in democratic processes (Brehm and Rahn 1997; Burns, Kinder, and Rahn 2003; Hetherington 1998; Putnam 2001; Rahn and Transue 1998; Uslaner 2002). In short, trust has been forwarded as a foundation for effective social, economic, and political life.

However, many scholars believe the study of trust relies on an oversimplified view of both the formation and function of trust (Burns, Kinder, and Rahn 2003). Much of this criticism is directed at the assumption that people apply broad attitudes about the trustworthiness of human beings or government in general to every trust-based relationship. The most important

departure from this "generalized trust" view is the idea that trust is domain-specific, where the basis of trust and the relationship between trust and behavior vary across domains. For example, Burns, Kinder, and Rahn (2003) find important differences in the dynamics of generalized trust, workplace trust, and neighborhood trust. Paraphrasing Hardin (1993), Kramer summarizes the domain-specific concept of trust as "a threepart relation involving properties of a truster, attributes of a trustee, and a specific context or domain over which trust is conferred" $(1999,574)$.

This paper takes a step down the road towards a domain-specific understanding by integrating three theoretical frameworks to explain policy trust, and testing this integrated perspective in the specific domain of agricultural water policy. The three theoretical approaches are Levi's (2000) transaction cost theory, Sabatier and Jenkins-Smith's (1993) Advocacy Coalition Framework, and Rotter's $(1971,1980)$ generalized trust framework, which has dominated all but the most recent political science research on trust. These frameworks share a common definition of trust as expectations about whether or not a trustee, in the context of a risky exchange relationship, will behave in a manner beneficial or at least not detrimental to the truster. For political science, the theories also share a mutual interest in trust as shaping the relationship between citizens and political authorities. Where the

The Journal of Politics, Vol. 69, No. 1, February 2007, pp. 237-250 
theories differ is on what they hypothesize as the "bases" of trust, which are the factors that lead a truster to view an actor as more or less trustworthy (Kramer 1999). The analysis here attempts to identify whether or not there is a dominant basis for policy trust or whether the theories are mutually reinforcing.

The analysis examines these theories in the domain of agricultural water policy, more specifically collaborative watershed management within the Sacramento Valley Water Quality Coalition (hereafter Coalition; see http://www.svwqc.org/ for more details). Trust is important in this domain because the Coalition directly targets the collective-action problem of nonpoint source pollution. Nonpoint source pollution comes from multiple, dispersed agricultural sources, which means that improving water quality requires the combined efforts of most farmers in a watershed. Furthermore, nonpoint source pollution is hard to monitor and reacts with aquatic ecosystems in complex ways, making it difficult to link farmer behavior and environmental outcomes.

Because individual farmers cannot make a large difference in overall water quality and behavior is costly to monitor, each farmer has an incentive to free ride on the often expensive pollution control efforts of others. Cooperating farmers risk investing in pollution control practices that have little payoff because others are not investing; farmers generally do not want to receive the "sucker's" payoff. Farmers' payoffs also depend heavily on the decisions of a wide variety of nongovernmental organizations and government agencies involved with policy implementation. These organizations affect outcomes by supplying information, monitoring behavior, providing positive incentives for cooperation, and sometimes enforcing regulations. Many researchers agree trust is a critical resource for sustaining cooperation in these situations, where the utility of the truster depends on the strategic choices of trustees (Coleman 1990; Ostrom 1998; Williamson 1996).

The data comes from a mail survey of 821 farmers who are eligible for the Coalition. A battery of social network questions asks each farmer about the trustworthiness of 21 different agencies and organizations (including other farmers) involved with policy implementation, along with the bases of trust identified by each theoretical perspective. Farmer-organization dyads provide the unit of analysis for statistical tests, and the structure of the data should be kept in mind throughout the discussion. To foreshadow, the results of the analysis suggest that the dynamics of trust depend heavily on two factors present in all policy domains: the distribution of political interests and institutional structure of government. Knowing that the dynamics of trust are not monolithic but rather nuanced and contextual is critically important from the broader political science perspective, which views trust as a central feature of democratic governance.

\section{Theoretical Frameworks for Understanding Trust in a Policy Domain}

The analysis considers three theoretical frameworks to explain policy trust: the generalized trust approach first established by Rotter (1971, 1980), Levi's (2000) transaction cost theory, and Sabatier and JenkinsSmith's Advocacy Coalition Framework (1993). The next sections describe the specific hypotheses derived from each framework about the bases of policy trust.

\section{The Generalized Trust Framework}

The generalized trust framework hypothesizes that the bases of trust are general predispositions on the part of an individual to trust other people or government. Rahn and Transue (1998) describe generalized trust as a "standing decision" to give most people the benefit of the doubt. These predispositions reflect general views on human nature and society that are inherited or learned in early childhood and are adjusted over the lifetime of an individual in response to many social experiences. Regardless of how the updating process works, the generalized trust framework suggests that especially when entering new relationships with an individual or government agency, these predispositions will provide a foundation for the development of behavioral expectations. Kramer (1999) refers to the role of generalized attitudes as the "dispositional" basis of trust.

The generalized trust framework is the foundation of the original trust research done in the context of the National Election Studies and the General Social Survey. These studies use generalized questions about social and government trust such as "Generally speaking, would you say that most people can be trusted, or that you can't be too careful in dealing with people?," and "How much of the time do you think you can trust the government in Washington to do what is rightjust about always, most of the time, or only some of the time?" While this type of "thin" or "moralistic" (Uslaner 2002) trust can be useful for diffuse support of government (Hetherington 1998) or establishing expectations about unknown people (Putnam 2001), 
the utility of general dispositions may be reduced in the case of "thick" relationships that provide more detailed information about a trustee.

This paper examines three generalized trust attitudes: trust in government, external political efficacy, and social trust in other people. Trust in government is relevant because the outcomes of public policy are shaped by the behaviors of the many different government agencies involved with policy implementation. Similarly, external political efficacy - the idea that government is responsive to the demands of citizens-has been directly linked to generalized political trust (Craig 1979; Craig, Niemi, and Silver 1990). External political efficacy may even be more relevant in the case of public policies such as the Coalition, where members of target groups can directly participate in decision making for policies that affect their welfare. General social trust is relevant because watershed collective-action problems involve the behavior of other people, including other farmers and personnel from nongovernmental and government organizations.

\section{The Transaction Cost Framework}

Levi's (2000) transaction cost theory of trust derives its name from the idea that trust reduces the need to invest in costly monitoring and enforcement institutions. In situations characterized by distrust, actors invest in monitoring and enforcement institutions to ensure cooperation and prevent exploitation. In situations characterized by high levels of trust, fewer resources are required for monitoring and enforcement institutions. According to this perspective, institutions and trust are largely substitutes for one another, and thus it is possible to have cooperation without trust.

Most relevant for this analysis, Levi (2000) argues that trust is history based, where trust thickens or thins as the history of interaction informs the truster about what Bacharach and Gambetta (2003) call the "trust-warranting properties" of the trustee: promise keeping, similarity of interests, and competence. Trust is warranted when you believe someone with similar interests is willing and capable of keeping promises. These three beliefs are the knowledge needed for a truster to form expectations about the behavior of a trustee. Hence, the most general hypothesis is that trust is positively related to beliefs about promise keeping, value similarity, and competence.

With its foundation in neoinstitutional economics, the transaction cost framework also emphasizes the role of institutional structures in shaping policy trust. Federalism provides an important institutional structure in the domain of agricultural water policy, because farmers may be less willing to trust institutionally "distant" agencies that infrequently interact with local communities. Institutional distance is partly a function of physical distance, where decision makers in state/federal capitals make decisions that affect local jurisdictions. Another component of institutional distance is that centralized institutions tend to make uniform decisions that have to filter through many organizational levels before being locally applied. The greater the institutional distance between a truster and trustee, the higher the transaction costs of developing trust-based relationships. The federalism hypothesis suggests farmers will trust local organizations the most, followed by state/regional, and then national organizations.

\section{The Advocacy Coalition Framework}

Sabatier and Jenkins-Smith's (1993) Advocacy Coalition Framework posits that people have belief systems hierarchically organized into sets of concrete and abstract idea elements. The lowest level of a belief system is comprised of secondary beliefs, which are concrete beliefs about elements of a policy domain, including the trustworthiness of specific actors. At a higher and more abstract level are policy-core beliefs, which define fundamental normative preferences regarding the process and goals of policymaking. Policy-core beliefs influence the formation of secondary beliefs because they act as cognitive filters, which affect information processing by causing people to resist (accept) information that is inconsistent (consistent) with their policy-core beliefs. ${ }^{1}$

According to the ACF, trust is a function of the similarity between the policy-core beliefs of the truster and those of the trustee (Leach and Sabatier 2005). People will trust actors who they believe have very similar beliefs and interests to their own, and their trust will decline as the difference in policy-core beliefs increases. Policy-core beliefs will have the strongest positive effect on trust when the trustee is most similar to the truster, and the strongest negative effect when the trustee is most different. The ACF's conception of trust is similar to what Kramer (1999) calls categorybased trust, where trust is "predicated on information regarding a trustee's membership in a social or

\footnotetext{
${ }^{1}$ The ACF also posits a third level of beliefs called deep core beliefs, which are fundamental views on human nature and influence both policy-core and secondary beliefs. Since I do not directly measure those beliefs in this paper, I do not discuss the influence of deep core beliefs on trust.
} 
organizational category," and members of the category have particular policy-core beliefs. Expectations about a trustee from a particular social category are often based on stereotypes, reputation, and other information gleaned from media and political discussion and do not necessarily rely on direct experience.

I will investigate two important policy-core beliefs in the agricultural water policy domain: economic conservatism and environmentalism. Economic conservatism focuses on the proper role of government regulation with respect to property rights and private natural resource-use decisions. People who score high on this scale believe resource decisions should be left to private actors and generally distrust regulatory agencies. Environmentalism refers to a general adherence to environmental values and the belief that environmental goals deserve equal or greater priority than economic productivity.

A stylized example from agricultural water policy serves to clarify the ACF hypothesis. Farmers tend to categorize policy organizations according to their perceived policy interests: regulatory agencies are viewed as serving environmentalists, while local agricultural agencies and private agricultural organizations are seen as serving the farmer. Thus, farmers view regulatory agencies as less trustworthy and local agricultural agencies as more trustworthy. Furthermore, the relationship between economic conservatism and trustworthiness will be strong and positive for agricultural service organizations and strong and negative for regulatory agencies. The converse will hold for environmentalism. Policy-core beliefs will have much smaller effects on organizations that are viewed as neutral.

\section{Research Design and Analysis}

The research is based on a cross-sectional mail survey during Winter 2004-2005 sent to all farmers who were considered eligible for Conditional Waivers in nine counties (Butte, Colusa, Glenn, Shasta, Solano, Sutter, Tehama, Yolo, and Yuba) in the Sacramento River watershed. The survey contained batteries of trust questions about governmental and nongovernmental organizations involved with agricultural water policy, measured views about Coalition effectiveness, participation, and a variety of other attitudes and individual characteristics. The survey was sent to a sample of 3,786 eligible farmers, with 821 responses (22\% response rate; see online appendix, Table A1, at http:// www.journalofpolitics.org/articles.html, for response rates and farm size by county). The vast majority of the nonresponses were from unreturned mail surveys.

It is important to remember that the Coalition was initiated in July 2003 and represents California's first attempt to broadly manage agricultural nonpoint source pollution. Thus, while 18 months had passed between Coalition initiation and the administration of the mail survey, full participation in the Coalition had not been achieved. Many farmers have also resisted the Coalition as an example of government interference with private economic decisions. Hence, the research reported here captures the Coalition groups at an early stage in the evolution of cooperation, where trust is a scarce resource, especially for relationships between farmers and the milieu of agricultural water policy organizations involved in implementation.

Survey information can be compared to the 2002 USDA Agricultural Census (Ag Census) to get a better idea of the representativeness of the sample. In terms of farm characteristics, the respondents are biased towards the larger and slightly richer farms in nearly every county. The mean difference between the respondent farm size and the average farm size in each county is 200 acres. The smallest farm in the entire sample is one acre, and the largest is 15,600 acres. The Ag Census reports $66 \%$ of the farms in the ninecounty region with annual sales less than $\$ 49,000$, $10 \%$ with \$50,000-99,999, and $24 \%$ with over $\$ 100,000$. The study respondents report $55 \%$ with less than $\$ 49,000$ in gross farm revenue, $11 \%$ with $\$ 50,000-99,999$, and $34 \%$ with over $\$ 100,000$. The sample includes some of the largest and richest farms in the region, with $54(7.5 \%)$ reporting gross farm income over $\$ 1$ million with an average farm size of 2,923 acres. $^{2}$

In terms of operator characteristics, the sample appears biased towards males; the Ag Census reports $31 \%$ of the operators are female in the nine counties, compared to $11 \%$ in the sample. However, there is no difference in the race of the operators; the Ag Census reports $86 \%$ of the operators are white compared to $85 \%$ in the sample. The respondents have spent an average of 25 years in the farming business and report working an average of 38 hours per week on farming activities. Twelve percent of the sample have an advanced degree, $43 \%$ have at least some type of college degree, $22 \%$ have some college experience,

${ }^{2}$ Part of the reason the sample farms look richer is that the Census collects information on sales, while I collected information on gross farm revenue, which includes sales plus additional income from rental payments and subsidies. 
$18 \%$ have only a high school diploma, and $4 \%$ did not graduate high school. ${ }^{3}$

There are two explanations for the observed sample differences. First, there is potentially a mismatch between my sample frame and the sample frame of the Agricultural Census. My sample frame was derived mostly from publicly available lists of registered pesticide users, which are most likely biased towards larger farms. Furthermore, while an individual farm might have a female operator, the male operators may disproportionately apply for the pesticide permits. Second, the Coalition also experiences difficulty reaching out to smaller and less profitable farms in each area; these farms are appear less likely to become involved in agricultural policy initiatives of any type. As will be seen in the data analysis, there is evidence that more financially secure farms are more likely to trust especially local agricultural agencies. However, the population of farmers that the sample does represent is the most critical for the successful implementation of water policy, because they have the largest per farm impact on water quality and also tend to be the economic and political leaders of the local agricultural communities. These farmers constitute what Lubell (2005) called the "vanguard of cooperation," where social capital and trust built first among the more involved farmers may spread over time to the rest of the community.

\section{Variable Construction: Measuring Policy Trust}

The survey asks farmers to indicate whether they completely trust or completely distrust (11-point scale; $0=$ complete distrust, $10=$ complete trust) each of 21 different governmental and nongovernmental organizations involved with agricultural water policy in the Sacramento River watershed (see online appendix for specific question wordings). The organizations range from local organizations like the County Farm Bureau and the Central Valley Regional Water Quality Control

\footnotetext{
${ }^{3}$ The years farming, work week, and education statistics are not strictly comparable to figures from the Agricultural Census, but these figures do not suggest any type of large or systematic bias. Better-educated farmers tend to have higher incomes (Pearson's $r=.10$ ) and be younger (Pearson's $r=-.09$ ). These patterns are typical of a demographic transition in agriculture to younger, better-educated farmers replacing the older, less-educated farmers. The education numbers in particular should help dispel the myth of farmers being a poorly educated community. For example, the 2000 Population Census reports $26 \%$ of Californians have a bachelor's degree or higher, while $46 \%$ of the farmer respondents report a bachelor's degree or higher.
}

Board, to federal agencies like the U.S. Department of Agriculture. The trust battery is structured similar to social network questions that ask people to characterize a set of self-reported contacts or a list of contacts provided by the researcher.

For the purpose of the analysis, I transformed the trust data into farmer-organization dyads. For example, there is one row in the data matrix for each farmer-California Farm Bureau dyad. These dyads are the units of analysis for the statistical models. Because farmers tended to answer these questions only for agencies they indicated some level of contact with, and some farmers completely skipped the trust questions, not all farmer-organization dyads are available for analysis for every farmer. Later, I will discuss how I use Heckman selection bias models to statistically correct for the nonrandom selection of observed dyads.

\section{Variable Construction: Independent Variables}

The independent variables for the generalized trust framework are measured with three disagree-agree (7-point scales; $0=$ disagree, $7=$ agree) questions adapted from the National Election Study and General Social Survey. Generalized trust in government is measured with the statement "You can always trust the government to do what is right." Generalized trust in other people is measured with the statement "Generally speaking, most people can be trusted." External political efficacy is measured with the statement "People like me don't have any say about what government does." Because each farmer answers the generalized trust questions only once, the same value applies to every dyad involving a particular farmer.

The trust-warranting properties identified by the transaction cost framework are measured in the same organizational network batteries described in the previous section. For each of the 21 organizations, the farmers indicate whether or not they believe the organization keeps promises (11-point scale; $0=$ never keeps promises, $10=$ always keeps promises), is competent (11-point scale; $0=$ completely incompetent, $10=$ completely competent), and has the same policy interests as the farmer (11-point scale; $0=$ Very similar policy interests, $10=$ very different policy interests). As discussed above, the transaction cost framework assumes these trust-warranting properties are the basis for the overall trust evaluation, and thus overall trust serves as a dependent variable. I will later discuss the viability of this assumption for cross-sectional data.

Federalism is measured with dichotomous $[0,1]$ dummy variables indicating whether or not the 


\section{Figure 1 Mean Values of Trust and Trust-Warranting Properties}

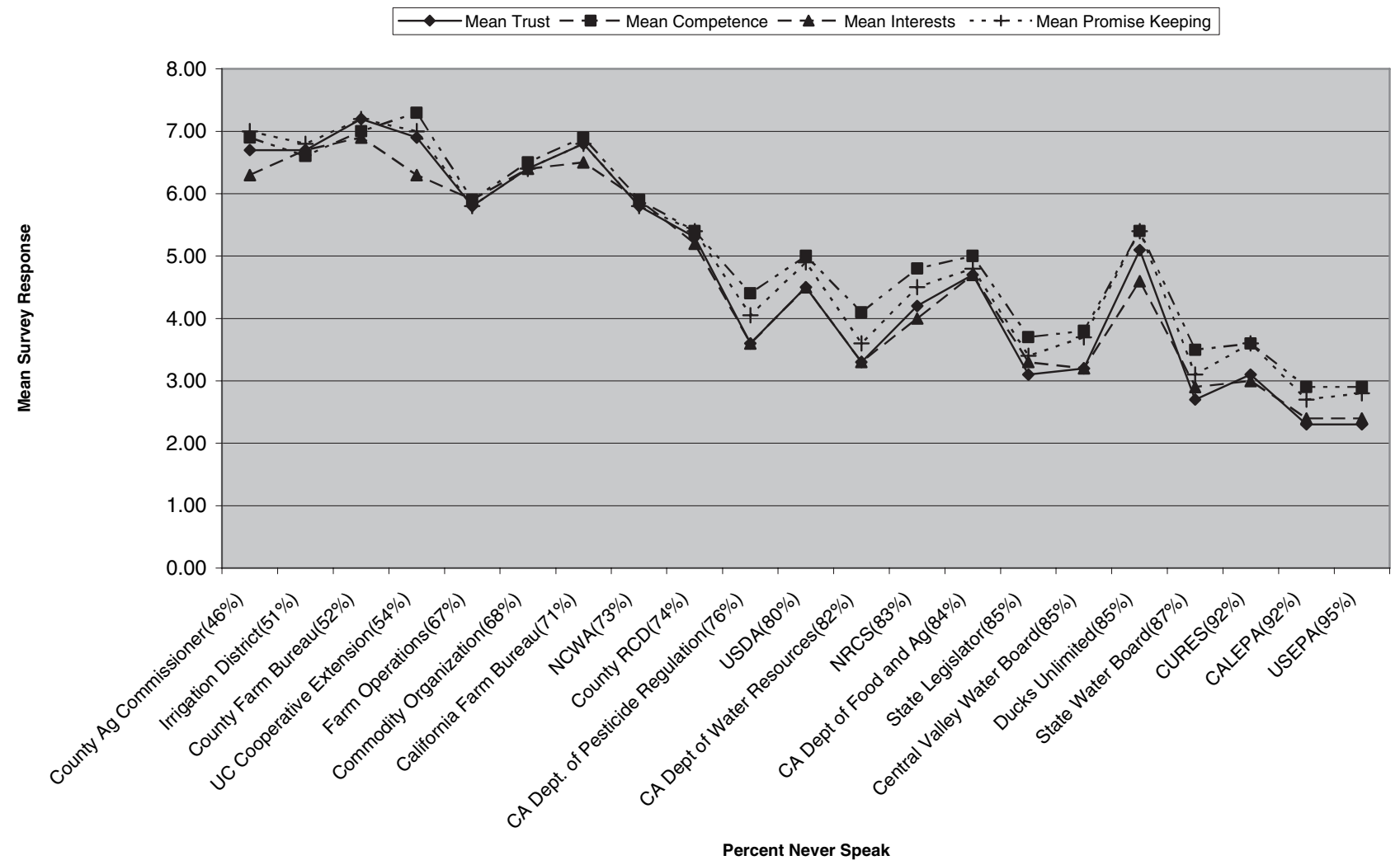

organization involved in a particular dyad is a regional/ state, or Federal agency. In all cases, local organizations are the baseline category and thus the federalism hypothesis predicts the dummy variable coefficients will be negative. For some analyses, there are only two levels of agencies; I will note this as necessary.

The policy-core beliefs identified by the ACF are measured with scales that take the average values of several individual disagree-agree (7-point scales; $1=$ Strongly disagree, $7=$ Strongly agree) questions. Environmentalism is a 2-item scale (Cronbach's alpha $=.63)$ that measures beliefs about the proper balance between the environment and economy; higher values indicate more pro-environmental beliefs. Economic conservatism is a 3-item scale (Cronbach's alpha $=.71)$ that measures beliefs about the proper role of government in the economy, and whether or not regulations are too tough on agriculture; higher values indicate more conservative responses.

\section{Descriptive Analysis: The Landscape of Trust}

For a basic idea of the landscape of trust in the Sacramento River watershed, Figure 1 presents the mean levels of trust, promise keeping, competence, and value similarity judgments for each of the 21 organizations listed in the trust battery. These are the central concepts identified by the transaction costs framework. The horizontal axis is organized from left to right in terms of increasing frequency of noncontact with that particular organization. For example, $95 \%$ of farmers report never contacting the U.S. Environmental Protection Agency about water quality policy, 68\% report never contacting a commodity organization, and 46\% report never contacting the County Agricultural Commissioner.

Figure 1 shows strong, positive relationships among trust, perceptions of trust-warranting properties, and frequency of interaction. The relationships among trust, frequency of contact, and trustwarranting properties are most likely dynamic and reciprocal and cannot be disentangled in a single cross-sectional study without strong instrumental variables. Frequency of contact and levels of trust are highest for actors that have pro-agricultural interests, which includes local service agencies and agricultural interest groups. The frequency of contact is lower for regulatory agencies and also for agencies that are at higher levels of the federal system. Overall, the patterns in Figure 1 strongly support the transaction costs 
TABLE 1 Organizational Types by Federal Level

\begin{tabular}{|c|c|c|c|}
\hline & Federal & State/Regional & Local \\
\hline Agricultural Interests & N/A & CA Farm Bureau & $\begin{array}{l}\text { Commodity Organization } \\
\text { County Farm Bureau } \\
\text { Other farm operations }\end{array}$ \\
\hline Coalition NGOs & N/A & $\begin{array}{l}\text { Ducks Unlimited } \\
\text { CURES } \\
\text { NCWA }\end{array}$ & $\mathrm{N} / \mathrm{A}$ \\
\hline Service Agencies & $\begin{array}{l}\text { NRCS } \\
\text { USDA }\end{array}$ & CDFA & $\begin{array}{l}\text { Irrigation District } \\
\text { County RCD } \\
\text { UC Cooperative Extension } \\
\text { County Ag. Commissioner }\end{array}$ \\
\hline Regulatory Agencies & USEPA & $\begin{array}{l}\text { State WRCB } \\
\text { Central Valley WRCB } \\
\text { CA Dept. of Pesticide Regulation } \\
\text { CA Dept. of Water Resources } \\
\text { CALEPA }\end{array}$ & N/A \\
\hline
\end{tabular}

Acronyms

NRCS: Natural Resources Conservation Services

USDA: United States Department of Agriculture

USEPA: United States Environmental Protection Agency

CDFA: California Department of Food and Agriculture

State WRCB: California State Water Resources Control Board

Central Valley WRCB: Central Valley Water Resources Control Board

CALEPA: California Environmental Protection Agency

CURES: Coalition for Urban-Rural Environmental Stewardship

NCWA: Northern California Water Association

RCD: Resources Conservation District

framework, but also bring up important measurement and causality issues that will be discussed later. ${ }^{4}$

The domain-specific view on trust suggests that even within the broad policy domain of agricultural water policy, not all trust relationships are created equal. It is likely that the structure of trust varies according to the nature of the relationship between the farmers and the watershed organizations. The transaction cost approach would hypothesize that institutional distance created by the structure of federalism is a key contextual variable. The ACF would hypothesize that a key contextual variable would be the congruence between the policy interests of the farmers and the policy interests of the organization. To explore this possibility, Tables 1 and 2 divide the organizations into four types by levels of the federal system: agricultural interests, agricultural service

${ }^{4}$ One interesting idiosyncrasy in Figure 1 is Ducks Unlimited, which has a high level of trust relative to contact frequency. There is a substantive explanation for this in the Coalition context, where Ducks Unlimited mainly represents farmers who manage wetlands for waterfowl hunting. While wetland managers are rare relative to agricultural production farms, they share many of the same values as production farmers, and sometimes even combine wetlands management with production agriculture. agencies, regulatory agencies, and Coalition nongovernmental groups. In a sense, these categorizations identify "subdomains" of the policy domain, and thus there may be different dynamics in the three-part relationship between truster, trustee, and context in which trust is conferred.

The policy interests dimension requires some elaboration. The rows of Tables 1 and 2 roughly divide organizations along a dimension from pro- to anti-agriculture, at least as perceived by the farmers. Agricultural interests are private, pro-agricultural political and economic groups. Service agencies are governmental agencies that provide some type of service to the agricultural industry, such as local Resource Conservation Districts. However, in the context of the Coalition, local service agencies often take a neutral stance as organizers and leaders of subwatershed groups. Regulatory agencies are government agencies that attempt to regulate the economic activities of agriculture; farmers typically view them as detrimental to agricultural profitability. Of particular importance are the Central Valley and State Water Resources Control Boards, which promulgated the new Coalition requirements. Coalition NGOs are the private, nongovernmental organizations that are 
TABle 2 Trust and Contact Frequency by Relationship Type and Federal Level

\begin{tabular}{lccc}
\hline & Federal & State Regional & Local \\
\hline Agricultural Interests & N/A & Trust $=.68$ & Trust $=.66$ \\
Coalition NGOs & & No Contact $=72 \%$ & Nontact $=62 \%$ \\
& N/A & Trust $=.48$ & N/A \\
Service Agencies & No Contact $=84 \%$ & Trust $=.47$ & Trust $=.65$ \\
& No Contact $=81 \%$ & No Contact $=85 \%$ & No Contact $=57 \%$ \\
Regulatory Agencies & Trust $=.23$ & Trust $=.30$ & N/A \\
& No Contact $=95 \%$ & No Contact $=85 \%$ & \\
\hline
\end{tabular}

involved with coordinating regional Coalition activities and strive to take a neutral position between the agricultural industry and regulatory agencies.

Table 2 demonstrates the usefulness of the categorization scheme by displaying the average level of trust (linearly rescaled to $0-1$ range) and frequency of no contact for each category. Agricultural interests and local service agencies have the highest levels of trust and contact, while federal regulatory agencies have the lowest levels. Coalition NGOs and service agencies at higher levels of the federal system are in the middle. The second column is particularly revealing, because it shows how trust and contact varies from high to low along the policy interest dimension for organizations at the same level of the federal system. I will maintain these broad distinctions in the multivariate models that follow in order to explore how the structure of policy trust varies for different types of relationships.

\section{Heckman Selection Bias Models: Correcting for Unobserved Dyads}

The next step is to test the hypotheses of each theoretical framework by statistically estimating the influence of trust-warranting properties, generalized trust, and social values on policy trust. Analysis of all farmer-organization dyads is not possible because respondents did not answer the trust questions for all organizations. Rather, respondents nonrandomly selected certain organizations on which they would answer questions. I correct for potential selection bias due to item nonresponse with Heckman models, which simultaneously estimate a probit "selection" equation on the full sample to predict which dyads are observed and a regression "outcome" equation for the subset which is observed (Greene 2000; Heckman 1976). The error terms of the outcome and selection equations are assumed to be correlated at some value $\rho \neq 0$. Although the selection equation may have substantive meaning, it is mainly used to correct the parameter estimates in the outcome equation, which are the main theoretical focus.

The selection equations include a set of variables related to the likelihood that a farmer would be exposed to the network of organizations involved with agricultural water policy. The implicit assumption is that farmers are more likely to answer the trust questions if they have heard about the organization. The selection variables include the number of years farming, education (7-point scale), subjective size of farm relative to the average ( $1-5$ Likert scale; $1=$ Much smaller than average, $5=$ Much larger), subjective wealth of farm (1-5 Likert scale; $1=$ Much worse off, $5=$ Much better off), and number of Coalition activities in which the farmer has participated (from a list of nine activities). ${ }^{5}$ A dummy variable for females is also included, because the smaller proportion of females with pesticide permits relative to the proportion of female operators identified by the Ag Census suggests that male operators may be taking the lead in interacting with public agencies. In general, the results of the selection equations suggest that better-educated, male operators on larger farms, who have participated in watershed management activities, are more likely to answer the trust questions (see appendix Tables A2 and $\mathrm{A} 3$, available at the JOP website, for results of selection equations).

The outcome equations include all of the variables identified by each theoretical framework as explanations of policy trust, which were discussed in detail above. The outcome equation also includes the subjective farm size and wealth variables as controls, because case study evidence suggests larger and richer

\footnotetext{
${ }^{5}$ Subjective perceptions of farm size and wealth are used because farmers do not like to provide specific information about income and farm size. They consider it private, and thus there is a high proportion of nonresponse on those variables. Furthermore, perceptions of size and wealth may drive decisions just as much as the objective farm characteristics.
} 
farms have thicker relationships with watershed management organizations. ${ }^{6}$ All of the Heckman models are estimated with maximum likelihood and use robust standard errors clustered by survey respondent to account for correlated errors among dyads from the same respondent. Overall, the results of the full Heckman models indicate significant correlations between the error terms of the outcome and selection equations. However, the slope coefficient estimates from the Heckman outcome equations vary only slightly from OLS regression estimates. This suggests that any omitted variables causing correlations between the error terms are not highly correlated with the independent variables in the outcome equations.

All attitude variables including the dependent variables are linearly rescaled to the $[0,1]$ range, thus the reported slope coefficients in the outcome equation can be interpreted as the change in the expected value (expressed as an absolute percentage of the range of the dependent variable in the sample) of the dependent variable moving across the entire range of the explanatory variable. For example, if the expected value of policy trust $=.10$ when environmentalism equals zero, and the regression coefficient for environmentalism $=.11$, then ceteris paribus the expected value of policy trust when environmentalism $=1$ (maximum value) will be .21 $(.10+.11=.21$, or an absolute change of $11 \%$ points). Another way to interpret the coefficients for the attitude variables is as the maximum possible effect of the variable.

\section{Results: Explaining Policy Trust}

The basic strategy of the analysis is to estimate Heckman models for each of the four groups of farmer-organization dyads: agricultural interests, Coalition NGOs, service agencies, and regulatory agencies. ${ }^{7}$ To test the transaction cost framework, I first estimated models using the single trust question

\footnotetext{
${ }^{6}$ One potential objection to this model specification is that all the variables included in the selection equation-not just subjective farm size and wealth - should be included as controls in the outcome equation, because previous studies have found education, income, and age to be positively related to trust. In preliminary regression analyses, I found that these variables were almost never significantly related to trust and therefore chose to exclude them from the outcome equation to help stabilize the numerical properties of the estimator. See Sartori (2003) for discussion about the stability of Heckman estimators under different assumptions.

${ }^{7}$ To evaluate the robustness of these results, I also estimated OLS regression models and ordered probit models on the observed dyads. The direction and statistical significance of the results are no different for the regression or ordered probit models (contact author for results). Overall, these results are remarkably robust to different model specifications.
}

as a dependent variable, with the trust-warranting properties as independent variables. On the basis of the strong causal assumption of no reciprocal relationships between trust and trust-warranting properties, the results mirror Figure 1 and support the transaction costs framework because nearly all the coefficients for beliefs about trust-warranting properties are significant, large and positive. None of the variables that operationalize the other theoretical frameworks are consistently significant. However, the assumption of no reciprocal relationships is probably not tenable in a cross-sectional analysis. Panel design or experimental studies will be needed to untangle the dynamic relationships between the attitude of trust and beliefs about trust-warranting properties. Therefore I only report the results of these models in the web appendix (Table A4).

An alternative approach is to think about trust from a measurement standpoint, and consider trust and trust-warranting properties all as measurements of the single underlying concept of policy trust. Indeed, equating the concept of trust with a variety of measurements about trust-warranting properties or other beliefs is by far the dominant measurement approach in the trust literature. For example, Brehm and Rahn (1997) construct a 3-item interpersonal trust scale that includes a question about trustworthiness, fairness, and helpfulness of other people (see citations in first paragraph for many other examples). To provide further hypothesis tests, Table 3 presents the outcome equations using a dependent variable that combines the trust and trust-warranting properties into a single 4-item scale (Cronbach's alpha $=.95$ ).

Table 3 reveals a much more interesting picture with respect to the other aspects of all three theoretical frameworks. The negative coefficients for state/ regional and federal agencies in the service and regulatory agency models reiterate the role of the institutional structure of federalism as predicted by the transaction cost framework. Farmers are less likely to trust institutionally distant organizations, even when those organizations directly support agricultural interests.

The regression coefficients for generalized trust in people and government are significant and positive in all but two instances, with some intriguing differences across types of organizations. For regulatory agencies, the strong influence of trust in government and the insignificance of trust in people reiterate the thin nature of those relationships. In contrast, government trust is not as important for agricultural interests, and social trust in general is significant for the organizational categories with thicker relationships. Although 


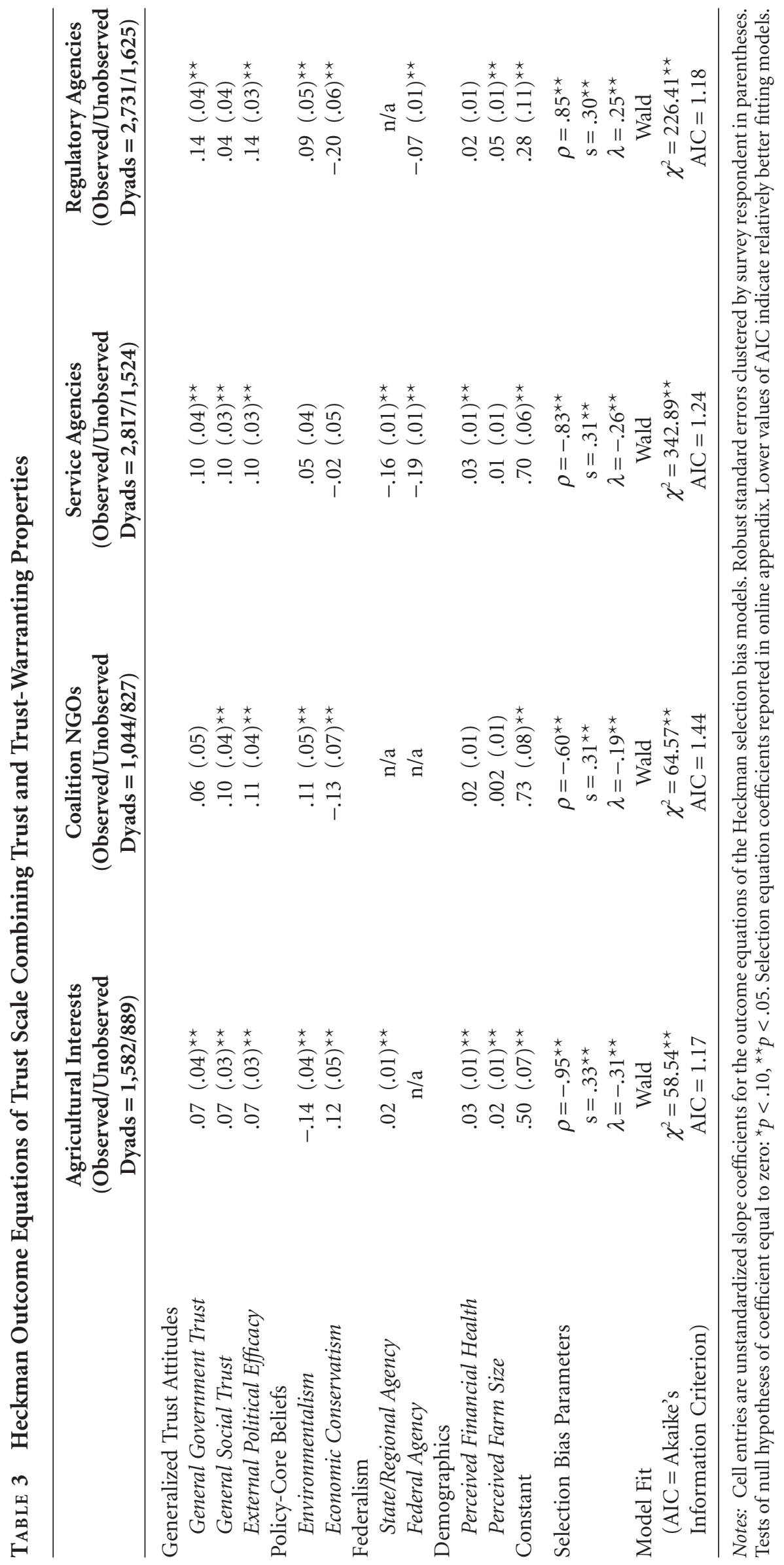


the statistical evidence is not definitive, the results suggest that social trust in people becomes more important as interaction becomes more frequent, allowing people to potentially divorce their trust expectations from any broad stereotypes about government agencies. The following quote from a personal interview with a Sacramento Valley farmer is illustrative:

Of course, by trust, I don't know if I necessarily mean believing everything they say but I will have more confidence in their abilities. I have great confidence in the abilities of the Glenn County Ag Commissioner's office because I see what they do. They're out there proving every day their competence and they're free to admit if they don't know, or if something is beyond their expertise they'll admit that. But I don't have that day-to-day contact with the Regional Board, it's more a longer time period between the contact. And they haven't come out and said "We don't know." In my family, we're firm believers that if you don't know, say so. Don't try to b.s. your way through something, to try and cover up.

External political efficacy has a consistently positive influence on trust for all organization types. The results suggest that generalized trust and political efficacy are important bases for more specific policy trust, but the basis shifts depending on the type of organization involved and the level of experience with specific individuals from that organization.

The results for the policy-core beliefs are consistent with the predictions of the ACF. For agricultural interests, who are most sympathetic to the farmers, environmentalism reduces the expected value of policy trust by 14 percentage points, while conservatism increases the expected value by 12 percentage points. Policy-core beliefs have the opposite effects for regulatory agencies, which have policy interests most dissimilar to those of farmers. Economic conservatism has the strongest effect for regulatory agencies, decreasing the expected value of policy trust by 20 percentage points. Reflecting their more neutral political roles, the effects of policy-core beliefs are insignificant for service agencies. Interestingly, contrary to their supposedly neutral role, the estimates for Coalition NGOs show a positive coefficient for environmentalism and a negative coefficient for economic conservatism. These results suggest that policy-core beliefs play a significant role in maintaining a division in policy trust between organizations and agencies perceived to be on different sides of a policy conflict. Policy-core beliefs accelerate the formation of thick and trusting relationships with organizations perceived to have similar policy interests and create barriers to the formation of trusting relationships with organizations perceived to have different interests.
The four-category classification scheme may possibly mask important differences between individual organizations. For example, the Coalition NGO category contains both the Northern California Water Association (NCWA, a nonprofit interest group) and the Coalition for Urban-Rural Environmental Stewardship (CURES, a for-profit consulting firm). While NCWA receives a fair amount of contact and trust from farmers, CURES seems to be viewed more like an environmental group, with low levels of trust and contact. This may explain why the estimates for Coalition NGOs are more like regulatory agencies than for service agencies.

Figure 2 provides a more detailed picture by reporting the slope coefficients for economic conservatism and environmentalism as estimated separately for each individual organization, using Heckman models and the exact same set of independent variables as in Table 3. The horizontal axis on Figure 2 is organized left to right according to decreasing policy interest similarity, with the average value of policy interest similarity in the parentheses after each organization label. Figure 2 shows how the influence of policy-core beliefs on policy trust changes along the gradient of policy interest similarity.

For regulatory organizations like the Water Boards, environmentalism has a strong positive effect, and economic conservatism has a strong negative effect. The magnitude of this divide moves towards zero as policy interests become more similar for neutral organizations and then reverses direction for the pro-agricultural service agencies and agricultural interests. For example, environmentalism has a strong negative effect and economic conservatism a strong positive effect on trust in the County Farm Bureau. There is also a slight asymmetry, with policy-core beliefs having a greater effect for those organizations that are most contrary to the interests of farmers. Policy-core beliefs do not have as strong an influence on the more neutral, bridging organizations like NCWA and UC Cooperative Extension. However, CURES and Ducks Unlimited are apparently viewed more like regulatory agencies, which means that not all of the Coalition NGOs are effectively mediating between competing interests.

The more detailed picture provides strong evidence for the predictions of the ACF-the influence of policy-core beliefs as a basis for trust is conditional on the similarity of interests between the truster and trustee. The development of policy trust can only be understood in the context of competing political values and the ideological differences between truster and trustee. 
Figure 2 Policy Interests and the Influence of Policy-Core Beliefs

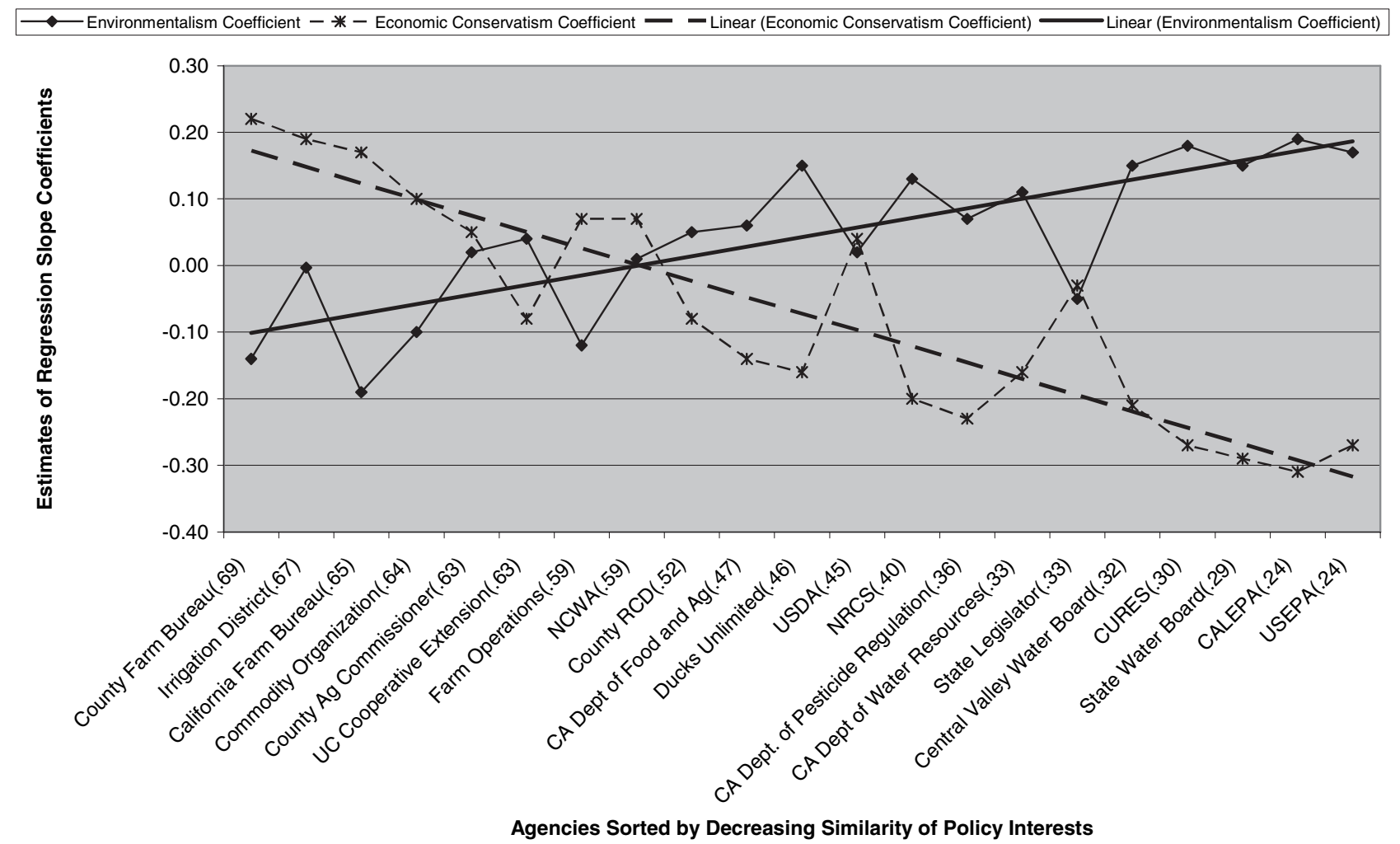

\section{Conclusions}

The analyses presented above provide support for integrating the three theoretical frameworks considered in this paper. As predicted by the transaction cost framework, there is a very strong link between policy trust, beliefs about trust-warranting properties, and the frequency of interaction. In fact, the link is so strong it makes more sense in a cross-sectional analysis to consider trust and trust-warranting properties as measurements of a single underlying concept. More research on the dynamic properties of trust will be needed to uncover which trust-warranting property is most important under what conditions, how trust influences perceptions of trust-warranting properties, and the functional forms of any updating or learning processes.

Generalized trust is also an important basis for the development of more specific policy trust. The analysis provides circumstantial empirical evidence that generalized trust in government has a stronger influence on trust in government agencies with which farmers have less frequent contact and "thinner" relationships. Generalized trust in people has a stronger influence for agricultural interests and service agen- cies, which tend to feature thicker relationships and more person-to-person contact. Generalized trust provides a baseline set of expectations, which are adjusted in light of more information about a specific organization. Political efficacy is a positive influence on policy trust for all types of relationships.

Perhaps most importantly, the structure of policy trust is heavily influenced by the political values and policy-core beliefs of farmers. Policy-core beliefs reinforce political divides by providing more stability to trusting relationships with organizations that have similar policy-core beliefs to farmers, while maintaining distrust in organizations that have dissimilar policy-core beliefs. When looking at Figure 2, it is easy to see which organizations are the most politicized in the context of agricultural water policy. It is no coincidence that organizations where environmentalism and conservatism have opposite influences on policy trust, such as the California Farm Bureau and the Central Valley Regional Water Quality Control Board, are also opposing parties in lawsuits over Coalition group policies. Similarly, organizations where policycore beliefs do not have such divergent influences are more likely to build bridges between competing advocacy coalitions. As policy issues cycle between conflict and cooperation, one hypothesis is that the influence 
of policy-core beliefs on policy trust will be less during periods of cooperation and stronger during periods of conflict.

Overall, the analysis provides some important findings about the structure of policy trust in the specific domain of agricultural water policy. The findings also provide some intriguing clues about the dynamics of trust in citizen-government relationships in general. In particular, different types of citizengovernment relationships appear to be characterized by two key contextual variables that influence how trust operates in a specific domain: ideological and institutional distance.

Ideological distance is important because all policy and political domains feature a gradient of interests on which political actors and citizens can be arranged (e.g., Figure 2). Citizens will have higher levels of trust in those actors who are closer in ideological distance. Furthermore, the influence of policycore beliefs shifts along the gradient of interests, having a very strong influence for ideologically distant and ideologically similar organizations, with less influence on more neutral organizations. Thus the information processing role of policy-core beliefs will tend to reinforce political divisions and is probably a fundamental feature of public policy. This hypothesis may also prove relevant to trust in a domain extensively studied by political scientists: national American electoral politics, which is often organized by the typical liberal-conservative dimension.

Institutional distance is important because it influences the "thickness" of the trust relationship. Citizens are less likely to have direct experience and interaction with institutionally distant federal and state agencies. Thus, they will not have much information about the trust-warranting properties of these actors and trust will depend more on stereotypes and generalized trust in government. Social trust and specific information about trust-warranting properties will have a stronger influence as institutional distance decreases.

These hypotheses require further testing in other specific policy and political domains, with an eye towards panel studies that untangle dynamic, reciprocal relationships. The study of trust may also benefit from explicit application of spatial theories of politics. However, care must be taken to avoid sacrificing a general understanding of how trust operates in society, especially if the bases and consequences of trust turn out to be very different in each domain. That certainly does not mean domain-specific research is not valuable. However, to preserve the ability to make more general statements, multilevel theory will be needed to understand the dimensions on which domains vary and then making predictions about the dynamics of trust based on domain characteristics.

\section{Acknowledgments}

Funding for this research provided by the Russell Sage Foundation Initiative on Trust and the California Policy Research Center. The author would like to thank Paul Sabatier, John T. Scholz, Mark Schneider, Allan Fulton, William Leach, Chris Weible, Mark Stephan, Edward Weber, Evan Ringquist, Clara Fishel, Anne Hansen, Paul Burow, and anonymous JOP reviewers for invaluable assistance.

Manuscript submitted 5 December 2005

Manuscript accepted for publication 17 March 2006

\section{References}

Bacharach, Michael, and Diego Gambetta. 2003. "Trust in Signs." In Trust in Society, ed. Karen Cook. New York: The Russell Sage Foundation, pp. 148-84.

Brehm, John, and Wendy Rahn. 1997. "Individual-Level Evidence for the Causes and Consequences of Social Capital." American Journal of Political Science 41 (3): 999-1023.

Burns, Nancy, Donald Kinder, and Wendy Rahn. 2003. "Social Trust and Democratic Politics." Presented at the annual meeting of the Midwest Political Science Association.

Craig, Stephen. 1979. "Efficacy, Trust, and Political Behavior: An Attempt to Resolve a Lingering Conceptual Dilemma." American Politics Quarterly 7 (2): 225-39.

Craig, Stephen C., Richard G. Niemi, and Glenn Silver. 1990. "Political Efficacy and Trust: A Report on the NES Pilot Study Items." Political Behavior 12 (3): 289-314.

Coleman, James. 1990. Foundations of Social Theory. Cambridge, MA: Harvard University Press.

Fehr, Ernst, Simon Gachter, and G. Kirchsteiger. 1997. "Reciprocity as a Contract Enforcement Device: Experimental Evidence." Econometrica 65 (4): 833-60.

Fukuyama, Francis. 1995. Trust. New York: Free Press.

Granovetter, Mark. 1983. “The Strength of Weak Ties: A Network Theory Revisited.” Sociological Theory 1: 201-33.

Greene, W. H. (2000). Econometric Analysis (4th ed.). Upper Saddle River, NJ: Prentice-Hall.

Hardin, Russell. 1993. "The Street-Level Epistemology of Trust." Politics and Society 21 (4): 505-29.

Hardin, Russell. 2002. Trust and Trustworthiness. New York: The Russell Sage Foundation.

Heckman, J. 1976. "The Common Structure of Statistical Models of Truncation, Sample Selection, and Limited Dependent Variables and a Simple Estimator for Such Models." Annals of Economic and Social Measurement 5 (Fall): 475-92.

Hetherington, Marc J. 1998. "The Political Relevance of Political Trust.” American Political Science Review 92 (4): 791-808. 
Kramer, Roderick. 1999. "Trust and Distrust in Organizations: Emerging Perspectives, Enduring Questions." Annual Review of Psychology 50: 569-98.

Leach, William D., and Paul A. Sabatier. 2005. "To Trust an Adversary: Integrating Rational and Psychological Models of Collaborative Policymaking." American Political Science Review 99 (4): 491-503.

Levi, Margaret. 1988. Of Rule and Revenue. Berkeley: University of California Press.

Levi, Margaret. 2000. "When Good Defenses Make Good Neighbors." In Institutions, Contracts, and Organizations: Perspectives from New Institutional Economics, ed. Claude Menard. Chichester, England: Edward Elgar, pp. 137-57.

Lubell, Mark. 2003. "Perceived Policy Effectiveness and Environmental Governance: Do Institutions Matter?" Political Research Quarterly 56 (3): 309-23.

Lubell, Mark. 2005. "Public Learning and Grassroots Cooperation." In Adaptive Governance and Water Conflict, eds. John T. Scholz and Bruce Stiftel. Washington, DC: Resources for the Future Press, pp. 174-84.

Mondak, Jeffery J., and Diana C. Mutz. 2001. "Involuntary Association: How the Workplace Contributes to American Civic Life." Presented at the annual meeting of the Midwest Political Science Association.

North, Douglass C. 1990. Institutions, Institutional Change, and Economic Performance. New York: Cambridge University Press.

Ostrom, Elinor. 1990. Governing the Commons. New York: Cambridge University Press.

Ostrom, Elinor. 1998. "A Behavioral Approach to the Rational Choice Theory of Collective Action." American Political Science Review 92 (1): 1-22.

Putnam, Robert. 2001. Bowling Alone: The Collapse and Revival of American Community. New York: Simon and Schuster.
Rahn, Wendy M., and John E. Transue. 1998. "Social Trust and Value Change: The Decline of Social Capital in American Youth, 1976-1995." Political Psychology 19 (3): 545-65.

Rotter, J.B. 1971. "Generalized Expectancies for Interpersonal Trust." American Psychologist 26 (5): 443-52.

Rotter, J.B. 1980. “Interpersonal Trust, Trustworthiness, and Gullibility." American Psychologist 35 (1): 1-7.

Sabatier, Paul, and Hank Jenkins-Smith. 1993. Policy Change and Learning: An Advocacy Coalition Approach. Boulder, CO: Westview Press.

Sartori, Anne E. 2003. "An Estimator for Some Binary-Outcome Selection Models without Exclusion Restrictions." Political Analysis 11 (2): 111-38.

Scheberle, Denise. 1997. Federalism and Environmental Policy: Trust and the Politics of Implementation. Washington, DC: Georgetown University Press.

Scholz, John T., and Mark Lubell. 1998a. "Adaptive Political Attitudes: Duty, Trust, and Fear as Monitors of Tax Policy." American Journal of Political Science 42 (2): 903-20.

Scholz, John T., and Mark Lubell. 1998b. "Trust and Taxpaying: Testing the Heuristic Approach to Collective Action.” American Journal of Political Science 42 (3): 903-20.

Uslaner, Eric M. 2002. The Moral Foundations of Trust. New York: Cambridge University Press.

Williamson, Oliver E. 1996. The Mechanisms of Governance. New York: Oxford University Press.

Mark Lubell is associate professor of environmental science and policy, University of California, Davis, Davis, CA 95616. 